\title{
Analisis Indikator Pendidikan: Partisipasi Pendidikan di Indonesia Periode 1994-2018
}

\author{
Abdul Fatah ${ }^{1}$, Muhammad Suhaili ${ }^{2 *}$, Isna Farida ${ }^{3}$ \\ ${ }^{1}$ MI Negeri 2 Lombok Tengah, ${ }^{2} *$ MA Negeri 2 Lombok Tengah, \\ ${ }^{3}$ MTs Negeri 2 Lombok Tengah, \\ Kemenag Kabupaten Lombok Tengah - Provinsi NTB \\ *Corresponding Author. Email: muhammadsuhaili0324@gmail.com
}

\begin{abstract}
This study aims to examine indicators of education in Indonesia based on the School Participation Rate (SPR), Rough Participation Rate (RPR), and Pure Participation Rate (PPR). This research used quantitative methods. The type of data used was secondary data obtained from the Central Statistics Agency (CSA) during the 1994-2018 period. The instrument used by BPS to collect data was a questionnaire through the National Survey and Census program (Susenas). The population involved in this study was all Indonesians based on age and education level. The data were processed using quantitative statistics with explorative descriptive analysis. The results showed that the SPR, RPR, and PPR in Indonesia based on age and level of education had an increasing trend. However, based on the average SPR, RPR, and PPR scores, educational participation has decreased with increasing age and level of education taken.
\end{abstract}

\begin{abstract}
Abstrak: Penelitian ini bertujuan untuk mengkaji indikator pendidikan di Indonesia berdasarkan Angka Partisipasi Sekolah (APS), Angka Partisipasi Kasar (APK) dan Angka Partisipasi Murni (APM). Penelitian ini menggunakan metode kuantitatif. Jenis data yang digunakan adalah data sekunder yang diperoleh dari Badan Pusat statistik (BPS) selama periode 1994-2018. Instrumen yang digunakan oleh BPS untuk mengumpulkan data adalah kuesioner melalui program Survei dan Sensus Nasional (Susenas). Populasi dalam penelitian ini adalah seluruh masyarakat Indonesia berdasarkan usia dan jenjang pendidikan. Data diolah menggunakan kuantitatif statistik dengan analisis deskriptif eksploratif. Hasil penelitian menunjukan bahwa APS, APK dan APM Indonesia berdasarkan usia, dan jenjang pendidikan trendnya mengalami peningkatan. Akan tetapi berdasarkan nilai rata-rata APS, APK, dan APM, partisipasi pendidikan mengalami penurunan seiring bertambahnya usia dan jenjang pendidikan yang ditempuh.
\end{abstract}

\section{Article History}

Received: 16-02-2021

Revised: 21-04-2021

Accepted: 23-07-2021

Published: 07-09-2021

\section{Key Words:}

School Participation Rate, Rough Participation Rate, Pure Participation Rate.

\section{Sejarah Artikel}

Diterima: 16-02-2021

Direvisi: 21-04-2021

Disetujui: 23-07-2021

Diterbitkan: 07-09-2021

\author{
Kata Kunci: \\ Partisipasi Pendidikan, Angka \\ Partisipasi Sekolah, Angka \\ Partisipasi Kasar. Angka \\ Partisipasi Murni.
}

How to Cite: Fatah, A., Suhaili, M., \& Farida, I. (2021). Analisis Indikator Pendidikan: Partisipasi Pendidikan di Indonesia Periode 1994-2018. Jurnal Kependidikan: Jurnal Hasil Penelitian dan Kajian Kepustakaan di Bidang Pendidikan, Pengajaran dan Pembelajaran, 7(3), 555-564. doi:https://doi.org/10.33394/jk.v7i3.3516

d.

https://doi.org/10.33394/jk.v7i3.3516

This is an open-access article under the CC-BY-SA License.

\section{Pendahuluan}

Keberhasilan pembangunan suatu bangsa sangat dipengaruhi oleh sumber daya manusia (SDM), oleh karena itu pendidikan merupakan sebuah keharusan bagi bangsa Indonesia karena pendidikan adalah dasar pembangunan SDM yang strategis (Ali, 2009; Idrus, 2012; Purwanto, 2006). Berdasarkan pasal 1 ayat (1) UU. No. 20 Tahun 2003 tentang Sistem Pendidikan Nasional menyatakan bahwa "Pendidikan adalah usaha sadar dan terencana untuk mewujudkan suasana belajar dan proses pembelajaran agar peserta didik secara aktif mengembangkan potensi dirinya untuk memiliki kekuatan spiritual keagamaan, pengendalian diri, kepribadian, kecerdasan, akhlak mulia serta keterampilan yang diperlukan dirinya, masyarakat, bangsa dan negara". Pendapat ahli mendefinisikan pendidikan sebagai 
pengaruh, bantuan atau tuntutan yang diberikan oleh orang yang bertanggungjawab kepada peserta didik (Ahmadi \& Ubhiyati, 2007). Suherman dalam (Sahwiyadi, 2018) mendefinisikan pendidikan sebagai proses penyampaian "nilai" atau "tatanan" dari pendidik kepada peserta didik agar peserta didik memperoleh IPTEK yang dapat digunakan dalam memenuhi kebutuhan hidup dan kehidupannya.

Berdasarkan pengertian pendidikan tersebut dapat dipahami bahwa pendidikan adalah suatu hal yang sangat esensial dalam proses pemanusiaan, terutama dalam masyarakat yang berbudaya, sehingga setiap warga negara memiliki hak mendapatkan pendidikan yang layak untuk mengembangkan potensi yang dimilikinya guna menjalani hidup di era globalisasi yang penuh persaingan (Nadziroh, Chairiyah, \& Pratomo, 2018; Tilaar, 2002). Hal ini juga sebagaimana diamanatkan oleh Undang-Undang Pasal 28C (1) yang menyatakan: "Setiap orang berhak mengembangkan diri melalui pemenuhan kebutuhan dasarnya, berhak mendapat pendidikan dan memperoleh manfaat dari ilmu pengetahuan dan teknologi, seni dan budaya, demi meningkatkan kualitas hidupnya dan demi kesejahteraan umat manusia".

Dewasa ini, kondisi pendidikan di Indonesia belum seperti yang dicita-citakan dan diamanatkan oleh undang-undang. Pemerataan pendidikan belum sepenuhnya tercapai. Bahkan isu pemerataan pendidikan bukan hanya di Indonesia tapi juga di negara lain (Chummings, 2014; David, 2004; Lynch \& Baker, 2005; Reay, 2018; Schutz, Ursprung, \& Woessmann, 2008; Tchamyou, 2018). Adapun pembangunan pendidikan di Indonesia memiliki dua dimensi penting yang menjadi permasalahan dalam pembangunan pendidikan hingga saat ini yaitu perluasan akses pendidikan dan pemerataan pendidikan (Hakim, 2016). Ketidakmerataan pendidikan meliputi dua aspek yaitu kualitas pendidikan (Service Learning) dan kuantitas pendidikan (akses, persebaran sekolah, perbandingan jumlah sekolah dengan penduduk) dan sebagainya (Wiratama, 2015).

Faktanya, hari ini masih banyak anak usia sekolah yang putus sekolah bahkan tidak memperoleh pendidikan sama sekali dengan berbagai faktor seperti: faktor ekonomi, perhatian orang tua, fasilitas pembelajaran, minat anak untuk sekolah, budaya dan faktor lingkungan (Ariyani, 2018; Dewi, Zukhri, \& Dunia, 2014; Mua, Manginsela, \& Baroleh, 2017; Natasha, 2013; Shemi, 2019; Wassahua, 2016). Hasil Susenas 2018 menunjukan sebesar 6,70\% penduduk usia 5 tahun keatas tidak/belum pernah sekolah (BPS, 2018). Selain itu, berdasarkan data BPS angka buta aksara juga masih cukup tinggi terutama 6 Provinnsi di daerah Indonesia bagian timur mencapai diatas $4 \%$ meliputi: Provinsi Papua, Nusa Tenggara Barat, Nusa Tenggara Timur, Sulawesi Barat, Sulawesi Selatan, dan Kalimantan Barat (BPS, 2018; Nugraheny, 2019). Secara kualitas SDM, berdasarkan data Human Develpoment Index (HDI) yang di rilis oleh UNDP, Indonesia berada diurutan ke-116 dunia, berada di bawah 5 negara angggota ASEAN lainnya dengan peringkat yang terpaut cukup jauh yaitu: Singapura peringkat ke-9, Brunei Darussalam ke-39, Malaysia ke-57, Thailand ke-83 dan Filipina peringkat ke-113 (UNDP, 2017).

Berdasarkan uraian diatas, maka perlu dilakukan analisis untuk memperoleh gambaran pendidikan di Indonesia berdasarkan partisipasi pendidikan. Penelitian ini bertujuan untuk menganalisis indikator pendidikan yaitu Angka Partisipasi Sekolah (APS), Angka Partisipasi Kasar (APK) dan Angka Partisipasi Murni (APM). APS adalah angka yang menunjukan proporsi anak sekolah pada usia jenjang pendidikan dalam usia yang sesuai dengan jenjang pendidikan tersebut, kegunaannya adalah untuk mengetahui tingkat partisipasi pendidikan atau jumlah masyarakat yang memperoleh pendidikan pada usia sekolah tertentu. APK adalah proporsi anak sekolah pada satu kelompok usia tertentu yang bersekolah pada jenjang yang sesuai dengan kelompok usianya, kegunaannya adalah untuk mengetahui jumlah siswa yang bersekolah pada jenjang tertentu. Adapun APM adalah 
proporsi anak sekolah pada suatu jenjang tertentu dalam kelompok usia yang sesuai dengan jenjang pendidikan tersebut, kegunannya adalah untuk mengetahui jumlah anak yang sekolah pada jenjang yang sesuai dengan usianya (BPS, 2019; Kemendikbud, 2017).

$$
\begin{aligned}
& \text { APS } 7-12 \text { th }=\frac{\text { JumlahPendudukyan gMasihSekolah } 7-12 \text { th }}{\text { JumlahPendudukUsiu } 7-12 t h} \times 100 \\
& \text { APK } /-12 \text { th }=\frac{\text { JumlahPendudukyangMasihSekalahdisD /MI }}{\text { JumlahPendudukUsia } 7-12 t h} x 100 \\
& \text { AYM SD/MI } /-12 \text { th }=\frac{\text { JumlahMuridSDMIUsiu } /-12 t h}{\text { JumlahPendudukU siw } 7-12 t h} \times 100
\end{aligned}
$$

Catatan:

APS : Kelompok usia sekolah (7-12 tahun, 13-15 tahun, 16-18 tahun dan 19-24 tahun)

APK :Jenjang Pendidikan SD/MI, Angka Partisipasi Kasar (APK) SMP/MTs, Angka Partisipasi Kasar SM/MA, atau Angka Partisipasi Kasar Perguruan Tinggi (PT).

APM : Jenjang SD/MI usia 7-12 tahun, SMP/MTs: usia 13-15 tahun, SM/MA : usia 16 -18 tahun, dan Perguruan tinggi: usia 19-24 tahun.

(Sumber: BPS, 2021).

\section{Metode Penelitian}

Penelitian ini menggunakan pendekatan kuantitatif statistik dengan analisis deskriptif eksploratif. Penelitian deskriptif adalah penelitian yang bertujuan untuk menjelaskan suatu peristiwa, keadaan, objek baik berupa orang, atau segala sesuatu yang berhubungan dengan variabel yang bisa dijelaskan menggunakan angka-angka maupun kata-kata tanpa melakukan treatmen apapun terhadap variabel (Punaji, 2010; Sukmadinata, 2012). Penelitian deskriptif eksploratif bertujuan menggambarkan keadaan, fenomena tanpa melakukan uji hipotesis tertentu tetapi hanya menggambarkan apa adanya suatu variabel, gejala dan keadaan (Arikunto, 2002).

Jenis data yang digunakan adalah data sekunder yang diperoleh dari Badan Pusat Statistik (BPS) tentang APS, APK dan APM pendidikan formal selama periode 1994-2018. Instrumen yang digunakan oleh BPS untuk mengumpulkan data adalah kuesioner melalui program Survei dan Sensus Nasional (Susenas). Populasi dalam penelitian ini adalah seluruh masyarakat Indonesia berdasarkan usia dan jenjang pendidikan. Adapun teknik analisis data menggunakan kuantitatif statistik untuk memperoleh data statistik seperti mean, median, mode, range, max, min, varian dan sum dengan bantuan program IBM SPSS Statistic Versi 22.

\section{Hasil Penelitian dan Pembahasan}

Berdasarkan hasil analisis data Angka Partisipasi Sekolah (APS) selama 25 tahun terahir (periode 1994-2018) pada Tabel 1 menunjukan bahwa nilai rata-rata (mean) usia 7-12 tahun sebesar $96.9146(96,92 \%)$, usia 13-15tahun sebesar $84.3073(84,31 \%)$, usia 16-18 tahun sebesar $56.2346(56,24 \%)$ dan usia 19-24 tahun sebesar 15.0214 (15,02\%). Angka Partisipasi Sekolah (APS) paling tinggi terjadi pada usia 7-12, kemudian 13-15 tahun, selanjutnya16-18 tahun, sedangkan paling rendah tingkat APS nya adalah usia 19-24 tahun. Selama periode 1994-2018, APS maximum untuk usia 7-12 tahun sebesar 99,11\% dan minimum sebesar 93,94\%. Usia 13-15 tahun nilai maximum sebesar 95,23\%, minimum sebesar 72,39\%. Usia 16-18 tahun nilai maximum sebesar 71,82\%, minimum sebesar 44,65\%, sedangkan usia 19-24 tahun memperoleh nilai maximum sebesar $24,67 \%$ dan nilai minimum sebesar 11,38\%. Adapun berdasarkan nilai range menunjukan bahwa selama periode 1994- 
2018 setiap jenjang usia mengalami peningkatan APS yaitu: 7-12 tahun sebesar 5,17\%, 13-15 tahun sebesar 22,84\%, 16-18 tahun sebesar 27,17\% dan 19-24 tahun meningkat sebesar 13,29\%. Berdasarkan data pada Tabel 1 dapat disimpulkan bahwa semakin tinggi usia, nilai rata-rata (mean) APS semakin rendah. Penjelasan lebih lanjut akan diuraikan pada bagian pembahasan.

Tabel 1. Deskripsi Angka Partisipasi Sekolah (APS)

\section{Statistics}

\begin{tabular}{lcccc}
\hline & $\mathbf{7 - 1 2 T h}$ & $\mathbf{1 3 - 1 5 T h}$ & $\mathbf{1 6 - 1 8 T h}$ & $\mathbf{1 9 - 2 4}$ \\
\hline Valid & 25 & 25 & 25 & 25 \\
\hline Missing & 0 & 0 & 0 & 0 \\
\hline Mean & 96.9146 & 84.3073 & 56.2346 & 15.0214 \\
\hline Std. Error of Mean & .32541 & 1.39849 & 1.72162 & .95378 \\
\hline Median & 97.3900 & 84.0800 & 53.9200 & 12.4300 \\
\hline Mode & $93.94^{\mathrm{a}}$ & $72.39^{\mathrm{a}}$ & $44.65^{\mathrm{a}}$ & $11.38^{\mathrm{a}}$ \\
\hline Std. Deviation & 1.62703 & 6.99246 & 8.60810 & 4.76892 \\
\hline Variance & 2.647 & 48.894 & 74.099 & 22.743 \\
\hline Range & 5.17 & 22.84 & 27.17 & 13.29 \\
\hline Minimum & 93.94 & 72.39 & 44.65 & 11.38 \\
\hline Maximum & 99.11 & 95.23 & 71.82 & 24.67 \\
\hline Sum & 2422.87 & 2107.68 & 1405.86 & 375.54 \\
\hline
\end{tabular}

a. Multiple modes exist. The smallest value is shown

Hasil analisis data Angka Partisipasi Kasar (APK) pada Tabel 2 menunjukan bahwa selama periode 1994-2018, jenjang SD/MI memiliki nilai rata-rata (mean) APK paling tinggi yaitu 1.0785E2 (lebih dari sratus persen), sedangkan jenjang SMP/MTs sebesar 81.0466 (81,05\%), selanjutnya jenjang SMA/MA sebesar 58.6520 (58,65\%) sedangkan jenjang Perguruan Tinggi (PT) sebesar 15.0338 (15,03\%). Selama periode 1994-2018, APK maximum untuk jenjang SD/MI sebesar $111,63 \%$ dan minimum sebesar $102,42 \%$. Jenjang SMP/MTs nilai maximum sebesar 91,23\%, minimum sebesar 64,36\%. Jenjang SMA/MA nilai maximum sebesar $82,25 \% \%$, minimum sebesar $42,43 \%$, sedangkan jenjang Perguruan Tinggi (PT) memperoleh nilai maximum sebesar $25,76 \%$ dan nilai minimum sebesar $9,55 \%$. Adapun berdasarkan nilai range menunjukan bahwa selama periode 1994-2018 setiap pendidikan mengalami peningkatan APK yaitu: jenjang SD/MI sebesar 9,21\%, jenjang SMP/MTs sebesar 26,87\%, jenjang SMA/MA sebesar 39,82\% dan jenjang Perguruan Tinggi (PT) meningkat sebesar 16,21\%. Berdasarkan data pada Tabel 2 dapat disimpulkan bahwa semakin tinggi jenjang pendidikan maka nilai rata-rata (mean) APK semakin rendah. Penjelasan lebih lanjut akan diuraikan pada bagian pembahasan.

Tabel 2. Deskripsi Angka Partisipasi Kasar (APK)

\begin{tabular}{lcccc}
\hline Statistics & & & & \\
& SD/MI & SMP/MTs & SMA/MA & Perguruan Tinggi \\
\hline Valid & 25 & 25 & 25 & 25 \\
\hline Missing & 0 & 0 & 0 & 0 \\
\hline Mean & $1.0785 \mathrm{E} 2$ & 81.0466 & 58.6520 & 15.0338 \\
\hline Std. Error of Mean & .39983 & 1.50416 & 2.51744 & 1.14161 \\
\hline Median & $1.0768 \mathrm{E} 2$ & 81.3800 & 56.6900 & 12.1600 \\
\hline & & Jurnal Kependidikan Vol. 7. No. 3 : September 2021
\end{tabular}

Copyright (C) 2021, Fatah, A., Suhaili, M., \& Farida, I. 


\begin{tabular}{lcccc}
\hline Mode & $107.13^{\mathrm{a}}$ & 81.09 & $42.43^{\mathrm{a}}$ & $9.55^{\mathrm{a}}$ \\
\hline Std. Deviation & 1.99915 & 7.52080 & $1.25872 \mathrm{E} 1$ & 5.70806 \\
\hline Variance & 3.997 & 56.562 & 158.437 & 32.582 \\
\hline Range & 9.21 & 26.87 & 39.82 & 16.21 \\
\hline Minimum & 102.42 & 64.36 & 42.43 & 9.55 \\
\hline Maximum & 111.63 & 91.23 & 82.25 & 25.76 \\
\hline Sum & 2696.33 & 2026.16 & 1466.30 & 375.85 \\
\hline
\end{tabular}

a. Multiple modes exist. The smallest value is shown

Hasil analisis data Angka Partisipasi Murni (APM) pada Tabel 3 menunjukan bahwa selama periode 1994-2018, jenjang SD/MI memiliki nilai rata-rata (mean) APM sebesar 93.6839 (93,68\%), sedangkan jenjang SMP/MTs sebesar 65.7515 (65,75\%), selanjutnya jenjang SMA/MA sebesar 45.2495 (45,25\%), sedangkan jenjang Perguruan Tinggi (PT) sebesar 11.3284 (11,33\%). Selama periode 1994-2018, APK maximum untuk jenjang SD/MI sebesar 97,48\% dan minimum sebesar 90,98\%. Jenjang SMP/MTs nilai maximum sebesar 78,75\%, minimum sebesar 50,03\%. Jenjang SMA/MA nilai maximum sebesar 60,53\%, minimum sebesar 32,60\%, sedangkan jenjang Perguruan Tinggi (PT) memperoleh nilai maximum sebesar $20,18 \%$ dan nilai minimum sebesar 7,15\%. Adapun berdasarkan nilai range menunjukan bahwa selama periode 1994-2018 setiap pendidikan mengalami peningkatan APM yaitu: jenjang SD/MI sebesar 6,49\%, jenjang SMP/MTs sebesar 28,72\%, jenjang SMA/MA sebesar 27,93\% dan jenjang Perguruan Tinggi (PT) meningkat sebesar 13,03\%. Berdasarkan data pada Tabel 3 dapat disimpulkan bahwa semakin tinggi jenjang pendidikan maka nilai rata-rata (mean) APM semakin rendah. Penjelasan lebih lanjut akan diuraikan pada bagian pembahasan.

Tabel 3. Deskripsi Angka Partisipasi Murni (APM)

\begin{tabular}{|c|c|c|c|c|c|}
\hline \multicolumn{6}{|c|}{ Statistics } \\
\hline & & SD/MI & SMP/MTs & SMA/MA & Perguruan Tinggi \\
\hline \multirow[t]{2}{*}{$\mathrm{N}$} & Valid & 25 & 25 & 25 & 25 \\
\hline & Missing & 0 & 0 & 0 & 0 \\
\hline \multicolumn{2}{|c|}{ Mean } & 93.6839 & 65.7515 & 45.2495 & 11.3284 \\
\hline \multicolumn{2}{|c|}{ Std. Error of Mean } & .37873 & 1.68645 & 1.81635 & .87414 \\
\hline \multicolumn{2}{|c|}{ Median } & 93.0400 & 66.5200 & 43.7700 & 8.8700 \\
\hline \multicolumn{2}{|c|}{ Mode } & 92.70 & $50.03^{\mathrm{a}}$ & $32.60^{\mathrm{a}}$ & 7.68 \\
\hline \multicolumn{2}{|c|}{ Std. Deviation } & 1.89364 & 8.43224 & 9.08175 & 4.37069 \\
\hline \multicolumn{2}{|c|}{ Variance } & 3.586 & 71.103 & 82.478 & 19.103 \\
\hline \multicolumn{2}{|c|}{ Range } & 6.49 & 28.72 & 27.93 & 13.03 \\
\hline \multicolumn{2}{|c|}{ Minimum } & 90.98 & 50.03 & 32.60 & 7.15 \\
\hline \multicolumn{2}{|c|}{ Maximum } & 97.48 & 78.75 & 60.53 & 20.18 \\
\hline \multicolumn{2}{|c|}{ Sum } & 2342.10 & 1643.79 & 1131.24 & 283.21 \\
\hline
\end{tabular}

a. Multiple modes exist. The smallest value is shown

\section{Pembahasan}

Angka Partisipasi Sekolah (APS), Angka Partisipasi Kasar dan Angka Partisipasi Murni (APM) adalah indikator untuk melihat partisipasi pendidikan. Partisipasi pendidikan merupakan tingkat partisipasi masyarakat dalam memperoleh pendidikan dalam jenjang usia 
dan jenjang pendidikan tertentu. Secara umum partisipasi pendidikan di Indonesia trendnya mengalami peningkatan setiap tahun baik berdasarkan APS, APK maupun APM. Ada pola yang menarik selama periode 1994-2018, yaitu rata-rata partisipasi pendidikan selalu mengalami penurunan seiring dengan bertambahnya usia dan semakin tingginya jenjang pendidikan yang ditempuh. Fenomena ini terjadi karena masyarakat tidak mampu untuk melanjutkan pendidikan ke jenjang yang lebih tinggi. Berdasarkan penelitian terdahulu disebutkan ada beberapa faktor yang menyebabkan tingkat partisipasi pendidikan rendah seperti faktor kemiskinan, kesadaran untuk melanjutkan sekolah rendah, faktor lingkungan, perhatian dari orang tua dan lain sebagainya (Malik \& Sumarno, 2016; Mua et al., 2017; Shemi, 2019). Angka kemiskinan di Indinesia masih cukup tinggi. Berdasarkan data BPS, persentase penduduk miskin pada bulan September 2020 mencapai 10,19\% atau sebanyak 27,55 juta orang (BPS, 2021). Hal ini memberikan dampak pada kemampuan masyarakat untuk melanjutkan pendidikan ke jenjang yang lebih tinggi.

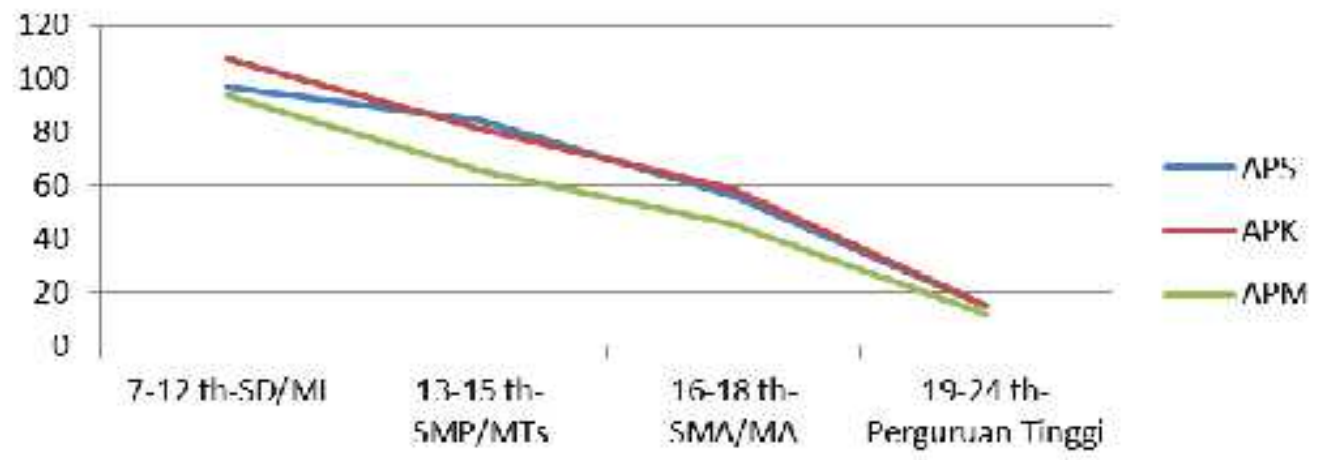

Gambar 1. Nilai Rata-Rata APS, APK dan APM (1994-2018)

Berdasarkan nilai rata-rata Angka Partisipasi Sekolah (APS) pada Tabel 1, Angka Partisipasi Kasar (APK) pada Tabel 2 dan Angka Partisipasi Murni (APM) pada Tabel 3 menunjukan bahwa usia 7-12 tahun dan usia 13-15 tahun memiliki tingkat partisipasi pendidikan yang tinggi yaitu: nilai rata-rata APS usia 7-12 tahun sebesar 96,92\%, APK sebesar 1.0785E2 (lebih dari seratus persen) dan APM sebesar 93,68\%. Sedangkan nilai ratarata APS usia 13-15 tahun sebesar 84,31\%, APK sebesar 81,05\% dan APM sebesar 65,75\%. Tingginya tingkat partisipasi pendidikan usia 7-12 tahun dan 13-15 tahun mengindikasikan bahwa program Wajib Belajar 9 tahun yang diterapkan oleh pemerintah telah berhasil meningkatkan partisipasi pendidikan di Indonesia. Seperti diketahui bahwa usia 7-12 tahun dan usia 13-15 tahun merupakan usia wajib belajar 9 tahun dengan menempuh jenjang SD/MI sampai SMP/MTs. Program Wajib Belajar 9 tahun merupakan realisasi dari amanat UUD 1945 pasal 1, UU. No 20 Tahun 2003 tentang Sistem Pendidikan Nasional dan Peraturan Pemerintah Republik Indonesia nomor 47 tahun 2008 tentang Wajib Belajar (Depdiknas, 2010). Selain itu, kesepakatan antar kepala negara seluruh dunia juga menekankzan pembangunan manusia yang disebut Millennium Development Goals (MDGs) pada tahun 2000 yang salah satu tujuannya adalah penuntasan pendidikan dasar bagi seluruh warga negara (Anwas, 2010; Kemendikbud, 2017). Tingginya patisipasi pendidikan pada usia ini juga didukung oleh minat masyarakat untuk sekolah karena tidak dikenakan biaya apapun (Supriyadi, 2010). Meskipun demikian pemerintah harus tetap meningkatkan angka partisipasi pendidikan dasar terutama di jenjang SMP karena nilai rata-rata APK hanya sebesar $65,75 \%$, hal ini dapat dilakukan dengan melibatkan semua pihak untuk mengatasi faktor-faktor yang menghambat terlaksananya kebijakan yang telah diterapkan oleh pemerintah (Berlian VA, 2011; Buwono, 2011; Malik \& Sumarno, 2016; Ulfatin, Mukhadis, \& Imron, 2010). 
Berdasarkan Tabel 1, Tabel 2 dan Tabel 3 dapat dilihat bahwa angka partisipasi pendidikan untuk usia 16-18 tahun yang merupakan usia sekolah jenjang SMA/MA masih cukup rendah, yaitu nilai rata-rata APS hanya 56,24\%, nilai rata-rata APK sebesar 58,65\% dan nilai rata-rata APM hanya 45,25\%. Selama periode 1994-2018 tingkat APS mengalami peningkatan sebesar 27,17\%, APK meningkat sebesar 39,82\% dan APM meningkat sebesar $27,93 \%$. Hal ini terjadi karena beberapa faktor seperti faktor kemiskinan, kesadaran untuk melanjutkan sekolah rendah, faktor lingkungan, perhatian dari orang tua dan lain sebagainya (Malik \& Sumarno, 2016; Mua et al., 2017; Shemi, 2019). Selain itu, program wajib belajar 12 tahun sampai hari ini masih wacana, retorika yang masih belum mendapatkan perhatian serius dari pemerintah sehingga belum maksimal(Prastiwi, 2019). Padahal wajib belajar 12 tahun merupakan salah satu target yang tercantum dalam Nawacita. Studi yang dilakukan JPPI menemukan bahwa 20 kabupaten atau kota yang dipilih secara acak belum ada yang memasukkan wajib belajar 12 tahun kedalam APBD (Rahayu, 2017).

Adapun angka partisipasi pendidikan untuk usia 19-24 tahun atau jenjang Perguruan Tinggi (PT) masih rendah jika dibandingkan dengan usia dan jenjang yang lain (7-12, 13-5 tahun dan SD/MI, AMP/MTs) (Istiqomah, Sukidin, \& Suharso, 2018). Pada Tabel 1, Tabel 2 dan Tabel 3 menunjukan bahwa nilai rata-rata APS sebesar 15,02\%. nilai rata-rata APK sebesar 15,03\% dan nilai rata-rata APM sebesar 11,33\%. Selama periode 1994-2018 angka partisipasi pendidikan Perguruan Tinggi (PT) berdasarkan APS hanya sebesar 13,29\%, APK meningkat sebesar 16,21\% dan APM meningkat sebesar 13,03\%. Tingkat partisipasi pendidikan jenjang Perguruan Tinggi terendah terjadi pada tahun 2006 dengan APS sebesar 11,38\% sedangkan tertinggi pada tahun 2017 dengan APS sebesar 24,67\%. Meskipun secara keseluruhan terjadi peningkatan angka partisipasi pendidikan jenjang Perguruan Tinggi, namun secara keseluruhan masih rendah jika dibandingkan dengan jenjang pendidikan yang lain. Hal ini terjadi karena beberapa faktor seperti faktor ekonomi yaitu terbentur biaya pendidikan untuk melanjutkan ke Perguruan Tinggi masih sangat mahal, faktor tingkat pendidikan orang tua, faktor lingkungan seperti teman sebaya, faktor motivasi belajar dan minat melanjutkan pendidikan (Arumsari, 2013; Darmawan, 2017; Fitriani, 2014; Rini, 2012; Suciningrum \& Rahayu, 2015).

Berdasarkan hasil penelitian dan pembahasan, ditemukan fakta bahwa semakin tinggi jenjang usia dan pendidikan, tingkat partisipasi pendidikan semakin menurun yaitu rata-rata Angka Partisipasi Sekolah (APS) usia 7-12 tahun sebesar 96,92\%, usia 13-15 tahun sebesar $84,31 \%$, usia 16-18 tahun sebesar 56,23\% dan usia 19-24 tahun sebesar 15,02\%. Fenomena ini terjadi karena masyarakat tidak mampu untuk melanjutkan pendidikan ke jenjang yang lebih tinggi. Berdasarkan penelitian terduhulu disebutkan ada beberapa faktor yang menyebabkan tingkat partisipasi pendidikan rendah seiring meningkatkanya usia dan jenjang pendidikan yang ditempuh seperti faktor kemiskinan, kesadaran untuk melanjutkan sekolah rendah, faktor lingkungan, perhatian dari orang tua dan lain sebagainya (Malik \& Sumarno, 2016; Mua et al., 2017; Shemi, 2019). Fenomena ini perlu mendapatkan perhatian dari pemerintah agar angka partisipasi pendidikan di Indonesia meningkat disetiap jenjang pendidikan dan usia.

\section{Kesimpulan}

Berdasarkan hasil penelitian ini dapat disimpulkan bahwa partisipasi pendidikan di Indonesia berdasarkan APS, APK dan APM trendnya mengalami peningkatan. Berdasarkan nilai ratarata Angka Partisipasi Sekolah (APS) menunjukan bahwa partisipasi pendidikan sangat tinggi, yaitu usia 7-12 tahun sebesar 96,92\%, usia 13-15 tahun sebesar 84,31\%, usia 16-18 tahun sebesar 56,23\% dan usia 19-24 tahun sebesar 15,02\%. Akan tetapi semakin besar usia, 
tingkat partisipasi pendidikan semakin menurun. Adapun partisipasi pendidikan berdasarkan nilai rata-rata Angka Partisipasi Kasar (APK) dan nilai rata-rata Angka Partisipasi Murni (APM) cukup tinggi untuk jenjang SMA/MA, sedangkan partisipasi pendidikan jenjang Perguruan Tinggi masih sangat kecil yaitu nilai rata-rata APK 15,03\% dan nilai rata-rata APM 11,33\%.

\section{Saran}

Ada beberapa solusi yang diajukan bagi dinas pendidikan dan pemerintah daerah untuk meningkatkan partisipasi pendidikan: Pertama, melakukan pendataan anak putus sekolah sampai ditingkat desa/kampung melalui sekolah-sekolah bekerjasama dengan RT/RW agar data yang diperoleh akurat. Kedua, sosialisasi pentingnya melanjutkan pendidikan sampai ke perguruan tinggi di lingkungan wali murid dan siswa. Ketiga, memberikan bantuan pendidikan secara selektif dan obyektif agar tepat sasaran. Keempat, melakukan pengawasan kelembaga-lembaga pendidikan untuk mengantisipasi pungutan liar yang memberatkan masyarakat untuk melanjutkan pendidikan.

\section{Daftar Pustaka}

Ahmadi, A., \& Ubhiyati, N. (2007). Ilmu Pendidikan. Jakrta: Rineka Cipta.

Ali, M. (2009). Pendidikan untuk pembangunan nasional: menuju bangsa Indonesia yang mandiri dan berdaya saing tinggi. Grasindo.

Anwas, O. M. (2010). Model Posdaya Dalam Penuntasan Wajib Belajar Pendidikan Dasar 9 Tahun. Jurnal Pendidikan Dan Kebudayaan, 16(2), 206-214. https://doi.org/10.24832/jpnk.v16i2.447

Arikunto, S. (2002). Prosedur suatu penelitian: pendekatan praktek. Edisi Revisi Kelima. Jakarta: Rineka Cipta.

Ariyani, S. N. Q. (2018). TREN ANGKA PUTUS SEKOLAH PENDIDIKAN SEKOLAH MENENGAH. Jurnal Kebijakan Pendidikan, 7(4), 440-451. Retrieved from http://journal.student.uny.ac.id/ojs/index.php/sakp/article/view/13142

Arumsari, T. (2013). Pengaruh Prestasi Belajar Dan Status Sosial Ekonomi Orang Tua Terhadap Minat Siswa Untuk Melanjutkan Studi Ke Perguruan Tinggi. Oikonomia: Jurnal Pendidikan Ekonomi, 2(3), 169-174.

Berlian VA, N. (2011). Faktor-faktor yang Terkait dengan Rendahnya Pencapaian Wajib Belajar Pendidikan Dasar 9 Tahun. Jurnal Pendidikan Dan Kebudayaan, 17(1), 4355. https://doi.org/10.24832/jpnk.v17i1.6

BPS. (2018). Statistik Kesejahteraan Rakyat Welfare Statistics (S. S. R. Tangga, Ed.). Jakarta: Badan Pusat Statistik.

BPS. (2019). Konsep APS, APK dan APM. Retrieved October 20, 2019, from Badan Pusat Statistik website: https://www.bps.go.id/subject/28/pendidikan.html\#subjekViewTab1

Buwono, H. S. (2011). Suatu Pendekatan Sosialisasi Dan Advokasi Penuntasan Wajib Belajar 9 Tahun Di Kabupaten Kubu Raya. Jurnal Pendidikan Sosiologi Dan Humaniora, 2(2), 208-218. Retrieved from http://jurnal.untan.ac.id/index.php/JPSH/article/view/391

Chummings, W. K. (2014). Education and equality in Japan. New Jersey: Princeton University Press.

Darmawan, I. (2017). Pengaruh Status Sosial Ekonomi Dan Lingkungan Teman Sebaya Terhadap Minat Melanjutkan Studi Ke Perguruan Tinggi Pada Siswa. Jurnal Pendidikan Dan Ekonomi, 6(2), 156-165. Retrieved from http://journal.student.uny.ac.id/ojs/ojs/index.php/ekonomi/article/view/6090/5816 
David, M. E. (2004). Equality and Equity in Higher Education: Learning to Develop New Paradigms from the US Experience? European Educational Research Journal, 3(4), 813-819. https://doi.org/10.2304/eerj.2004.3.4.8

Depdiknas. (2010). Peraturan Pemerintah Republik Indonesia Nomor 47 Tahun 2008 Tentang Wajib Belajar 9 Tahun. Jakarta: Departemen Pendidikan Nasional.

Dewi, N. A. K., Zukhri, A., \& Dunia, I. K. (2014). Analisis Faktor-Faktor Penyebab Anak Putus Sekolah 2012 / 2013. Jurnal Juruan Pendidikan Ekonomi, 4(1), 1-12. Retrieved from https://ejournal.undiksha.ac.id/index.php/JJPE/article/view/1898

Fitriani, K. (2014). Pengaruh Motivasi, Prestasi Belajar, Status Sosial Ekonomi Orang Tua Dan Lingkungan Sekolah Terhadap Minat Melanjutkan Pendidikan Ke Perguruan Tinggi Pada Siswa Kelas Xii Akuntansi Smk Negeri 1 Kendal. Economic Education Analysis Journal, 3(1), 152-159. Retrieved from http://journal.unnes.ac.id/sju/index.php/eeaj

Hakim, L. (2016). Pemerataan akses pendidikan bagi rakyat sesuai dengan amanat UndangUndang Nomor 20 Tahun 2003 tentang Sistem Pendidikan Nasional. EduTech: Jurnal Ilmu Pendidikan Dan Ilmu Sosial, 2(1), 53-64. Retrieved from http://jurnal.umsu.ac.id/index.php/edutech/article/view/575

Idrus, M. (2012). Mutu Pendidikan Dan Pemerataan Pendidikan Di Daerah/Quality of Education and Regional Educational Equity. PSIKOPEDAGOGIA Jurnal Bimbingan Dan Konseling, 1(2), 1-10. https://doi.org/10.12928/psikopedagogia.v1i2.4603

Istiqomah, A., Sukidin, \& Suharso, P. (2018). ANALISIS PARTISISPASI PENDIDIKAN PADA MASYARAKAT MISKIN DUSUN GUMUK LIMO DESA NOGOSARI KECAMATAN RAMBIPUJI KABUPATEN JEMBER. 12(2), 227-235. https://doi.org/10.19184/jpe.v12i2.8553

Kemendikbud. (2017). APK-APM.

Lynch, K., \& Baker, J. (2005). Equality in education:An equality of condition perspective. Theory and Research in Education, 3(2), 131-164. https://doi.org/10.1177/1477878505053298

Malik, H. K., \& Sumarno, S. (2016). Kepedulian orang tua terhadap pendidikan anak untuk menyelesaikan program wajar 9 tahun. Jurnal Pendidikan Dan Pemberdayaan Masyarakat, 3(1), 38-47. https://doi.org/10.21831/jppm.v3i1.8061

Mua, V. B., Manginsela, E. P., \& Baroleh, J. . (2017). Faktor-Faktor Penyebab Putus Sekolah Dari Anak Petani Dan Non-Petani Di Desa Sea Dan Desa Warembungan Kecamatan Pineleng Kabupaten Minahasa. Agri-Sosioekonomi, 13(3A), 313-322. https://doi.org/10.35791/agrsosek.13.3a.2017.18401

Nadziroh, Chairiyah, \& Pratomo, W. (2018). Hak Warga Negara Dalam Memperoleh Pendidikan. Trihayu: Jurnal Pendidikan Ke-SD-An, 4(3), 400-405. Retrieved from http://jurnal.ustjogja.ac.id/index.php/trihayu/article/view/2602

Natasha, H. (2013). Ketidaksetaraan Gender Bidang Pendidikan: Faktor Penyebab, Dampak, Dan Solusi. Marwah: Jurnal Perempuan, Agama Dan Jender, 12(1), 53-54. https://doi.org/10.24014/marwah.v12i1.513

Nugraheny, D. E. (2019). Mendikbud: Angka Buta Aksara di Enam Provinsi Masih Tinggi. Retrieved October 20, 2019, from Republika Online website: https://www.republika.co.id/berita/pendidikan/eduaction/pxftye409/mendikbudangka-buta-aksara-di-enam-provinsi-masih-tinggi

Prastiwi, D. (2019). Mendikbud Akui Wajib Belajar 12 Tahun Belum Maksimal. Retrieved October 23, 2019, from Merdeka website: 
https://www.merdeka.com/peristiwa/mendikbud-akui-wajib-belajar-12-tahun-belummaksimal.html

Punaji, S. (2010). Metode penelitian pendidikan dan pengembangan. Jakarta: Kencana.

Purwanto, N. A. (2006). Kontribusi Pendidikan Bagi Pembangunan Ekonomi Negara. Jurnal Manajemen Pendidikan, 2(2), 1-7. Retrieved from http://garuda.ristekdikti.go.id/journal/view/455?\&items $=10 \&$ page $=8$

Rahayu, C. M. (2017). JPPI: Wajib Belajar 12 Tahun Masih Sebatas Retrorika. Retrieved October 21, 2019, from https://news.detik.com/berita/d-3460243/jppi-wajib-belajar12-tahun-masih-sebatas-retrorika

Reay, D. (2018). Miseducation: inequality, education and the working classes. International Studies in Sociology of Education, 27(4), 453-456. https://doi.org/10.1080/09620214.2018.1531229

Rini, E. S. (2012). HUBUNGAN TINGKAT PENDIDIKAN ORANG TUA DAN PRESTASI BELAJAR SISWA DENGAN MINAT SISWA MELANJUTKAN STUDI KE PERGURUAN TINGGI PADA SISWA KELAS XI SMA NEGERI 1 KALASAN TAHUN AJARAN 2011/2012. Universitas Negeri Yogyakarta.

Sahwiyadi. (2018). Pendidikan anak perspektif munif chatib dan relevansinya dengan pendidikan anak dalam islam. Realita Jurnal Penelitian Dan Kebudayaan Islam, 16(2), 141-155. Retrieved from https://jurnal.iainkediri.ac.id/index.php/realita/article/view/1036

Schutz, G., Ursprung, H. W., \& Woessmann, L. (2008). Education policy and equality of opportunity. Kyklos, 61(2), 279-308. https://doi.org/10.1111/j.14676435.2008.00402.x

Shemi, H. (2019). Angka Putus Sekolah di Indonesia yang Mengkhawatirkan. Retrieved October 20, 2019, from idntimes website: https://www.idntimes.com/news/indonesia/helmi/angka-putus-sekolah-di-indonesiayang-mengkhawatirkan/full

Suciningrum, N. P., \& Rahayu, E. S. (2015). Pengaruh Status Sosial Ekonomi Orang Tua Dan Motivasi Belajar Tehadap Minat Melanjutkan Studi Ke Perguruan Tinggi Pada Kelas Xi Di Sma Pusaka 1 Jakarta. Jurnal Pendidikan Ekonomi Dan Bisnis (JPEB), 3(1), 1-21. https://doi.org/10.21009/jpeb.003.1.1

Sukmadinata, N. S. (2012). Metode Penelitian Pendidikan. Bandung: PT Remaja Rosdakarya.

Tchamyou, V. S. (2018). Education, lifelong learning, inequality and financial access: Evidence from African countries. Contemporary Social Science Journal of the Academy of Social Sciences, 1-9. https://doi.org/10.1080/21582041.2018.1433314

Tilaar, H. (2002). Perubahan Sosial dan Pendidikan. Jakarta: Grasindo.

Ulfatin, N., Mukhadis, A., \& Imron, A. (2010). Profil Wajib Belajar 9 Tahun dan Alternatif Penuntasannya. Jurnal Ilmu Pendidikan, 17(1), 36-45. Retrieved from http://journal.um.ac.id/index.php/jip/article/view/2618

UNDP. (2017). Human Development Data (1990-2017). Retrieved October 20, 2019, from Human Development Reports website: http://hdr.undp.org/en/data

Wassahua, S. (2016). Analisis Faktor - Faktor Penyebab Anak Putus Sekolah Di Kampung Wara Negeri Hative Kecil Kota Ambon. Al - Iltizam, 1(2), 93-113. Retrieved from https://jurnal.iainambon.ac.id/index.php/ALT/article/view/199

Wiratama, H. (2015). Analisis Persebaran Dan Ketersediaan Sekolah Menengah Di Kota Tanjungbalai Tahun 2014. Retrieved from http://digilib.unimed.ac.id/22138/ 